This item has been removed at the request of the author and is no longer available on this site but can be accessed via

http://www.enterprisingcompetencies.com/uploads/1/5/9/7/15971972/van_gelderen_2008_cdi.pdf 


\title{
Explaining entrepreneurial intentions by
} means of the theory of planned behavior

\author{
Van Gelderen, Marco
}

2006

http://hdl.handle.net/10179/9685

22/04/2023 - Downloaded from MASSEY RESEARCH ONLINE 